\section{Refractive error in school children in Campinas, Brazil}

\section{Erros refrativos em escolares de Campinas, Brasil}

Dear Editor,

Refractive errors such as myopia, astigmatism, and hyperopia are common ocular conditions that have been identified as concerns for public health and economy. The World Health Organization's "Vision 2020: The Right to Sight" initiative included the correction of refractive errors as one of the target areas to eliminate avoidable causes of visual impairment. Uncorrected refractive error is the most common cause of visual impairment in school-age children in both industrialised and developing countries ${ }^{(1)}$

The following report describes the prevalence of refractive error (myopia, hyperopia, and astigmatism) in school children in Campinas, Brazil.

This cross-sectional study was conducted in 2012. According to 2010 census $^{(2)}$, the population of Campinas, Brazil was approximately 1 million. Of these, 180,560 were within the age limits of the study and $126,392(70 \%)$ of them attended public schools. Four groups of children, from the $1^{\text {st }}$ (5-7 years-old), $5^{\text {th }}$ (9-11 years-old), $9^{\text {th }}(13-15$ years-old), and $12^{\text {th }}$ (16-18 years-old) levels of the Brazilian educational system, a total 1,100, were randomly selected from different public schools. The study has complete approval from the University of Campinas Research Ethics Committee. The research adhered to the principles of the Declaration of Helsinki.

The protocol for data collection included measurement of logMAR monocular distance, best-corrected visual acuity, and cycloplegic autorefraction (1\% cyclopentolate hydrochloride) using cycloplegic autorefraction (autorefractor model AR-8900; Topcon Corporation, Tokyo, Japan). The measurements were obtained after adding 1 drop of a topical anesthetic eye drop (proxymetacaine hydrochloride) in both eyes and waiting 2 minutes to achieve ocular surface anesthesia followed by addition of 2 drops of $1 \%$ cyclopentolate hydrochloride 10 minutes apart in each eye. Cycloplegic dilation was performed by an ophthalmic technologist. Five readings were recorded and the representative value, determined by the instrument, was used for further analysis. The representative value from the autorefractor was used to calculate spherical equivalent refraction (SER=sphere + cylinder/2). Myopia was defined as SER $\leq-0.50 \mathrm{D}$, hyperopia as $S E R \geq+2.00 \mathrm{D}$, refractive astigmatism as cylinder $\geq 1.00 \mathrm{D}$ if $-0.50>$ SER $<+2.00$, and emetropia as $-0.50>$ SER $<+2.00$ with cylinder $<1.00 \mathrm{D}^{(3)}$. All statistical analyses were carried out using PSPP software.

Among the 1,100 students invited to participate in the study, parental consent was obtained from 778 (70.7\%). 440 (56.5\%) were female. Table 1 describes the age and visual acuity of the participants. Table 2 describes the distribution according to the refractive errors.

The current paper presents a population-based data describing the prevalence of cycloplegic measures of refractive errors of students in Campinas, Brazil. There was a preponderance of emmetropes (75.1\%), and the prevalence of myopia was only $2.8 \%$ among the children of age group 5-7 years. Among the 16-18 years old age group, the prevalence of myopia increased sevenfold (19.3\%). Similar findings in young children have been reported by other studies ${ }^{(3)}$. By contrast, the prevalence of myopia in 7-years-old children in Singapore is $28 \%{ }^{(4)}$. One Brazilian study presented different results, but it was not possible to compare, as the protocols in our study are different from their study ${ }^{(5)}$.

One limitation of this study was the use of SER to classify myopia, which can result in over-estimation of prevalence in populations with significant levels of astigmatism. Despite this aspect, SER has been used to facilitate comparisons with other epidemiological studies of refractive error. Another limitation is that due to the limited data available for Brazil (a large and multi-ethnic country), it is unclear whether the prevalence of refractive errors in Campinas is representative of the Brazilian population as a whole.

Rodrigo Pessoa Cavalcanti Lira' ${ }^{1}$, Italo Fernandes do Espírito Santo ${ }^{2}$, Gustavo Lima do Valle Astur ${ }^{2}$, Diana Maziero², Thais Helena Moreira Passos ${ }^{2}$, Carlos Eduardo Leite Arieta ${ }^{1}$

Table 1. Distribution of students according to age and visual acuity

\begin{tabular}{|c|c|c|c|c|c|c|c|c|}
\hline & School level & Mean & SD & & Min & Max & Female & Male \\
\hline \multirow[t]{5}{*}{ Age (years) } & $1^{\text {st }}$ & 6.17 & 0.67 & & 5 & 7 & 6.19 & 6.15 \\
\hline & $5^{\text {th }}$ & 9.82 & 0.52 & & 9 & 11 & 9.77 & 9.88 \\
\hline & $9^{\text {th }}$ & 14.03 & 0.56 & & 13 & 15 & 13.99 & 14.09 \\
\hline & $12^{\text {th }}$ & 17.28 & 0.58 & & 16 & 18 & 17.32 & 17.22 \\
\hline & Total & 11.45 & 4.04 & & 5 & 18 & 11.61 & 11.24 \\
\hline Best-corrected visual acuity & $1^{\text {st }}$ & 85.08 & 6.34 & $P=0.410$ & 38.00 & 88.00 & 86.56 & 86.49 \\
\hline (ETDRS letters) & $5^{\text {th }}$ & 85.60 & 6.07 & & 38.00 & 88.00 & 86.02 & 86.22 \\
\hline \multirow[t]{3}{*}{ Right eye } & $9^{\text {th }}$ & 84.72 & 7.63 & & 38.00 & 88.00 & 84.35 & 85.31 \\
\hline & $12^{\text {th }}$ & 84.91 & 7.20 & & 38.00 & 88.00 & 85.25 & 85.19 \\
\hline & Total & 85.47 & 6.73 & & 38.00 & 88.00 & 85.13 & 85.91 \\
\hline
\end{tabular}

Table 2. Distribution of students according to refractive errors

\begin{tabular}{lcccccc}
\hline School level & Myopia & Hyperopia & Astigmatism & Emmetropia & Total & $\mathbf{P}$ \\
\hline $1^{\text {st }}$ & 5 & 15 & 25 & 136 & 181 & $<0.001$ \\
$5^{\text {th }}$ & 17 & 18 & 36 & 195 & 266 & \\
$9^{\text {th }}$ & 21 & 8 & 27 & 111 & 167 & \\
$12^{\text {th }}$ & 32 & 2 & 36 & 94 & 164 & \\
Total & 75 & 43 & 124 & 536 & 778 & \\
\hline
\end{tabular}


Study conducted at Universidade Estadual de Campinas (UNICAMP), Campinas, SP - Brazil.

Department of Ophthalmologic, Universidade Estadual de Campinas (UNICAMP), Campinas, SP - Brazil.

Universidade Estadual de Campinas (UNICAMP), Campinas, SP - Brazil.

Funding: This study was supported by FAPESP 2011/21773-2; FAPESP 2011/19835-0; FAPESP 2011/09514-1.

Disclosure of potential conflicts of interest: None of the authors have any potential conflicts of interest to disclose.

Corresponding author: Rodrigo Pessoa Cavalcanti Lira. Rua Irma Maria David, 200/1.302 - Recife PE - 52061-070 - Brazil - E-mail: rodrigopclira@hotmail.com

Project number and institution responsible for the approval of the Research Ethics Committee: UNICAMP 933/2011 - CAAE 0842.0.146.000-11

Submitted for publication: October 14, 2013

Accepted for publication: June 9, 2014

\section{REFERENCES}

1. Resnikoff S, Pararajasegaram R. Blindness prevention programmes: past, present, and future. Bull World Health Organ. 2001;79(3):222-6.

2. IBGE. São Paulo Campinas Censo Demográfico 2010: Resultados da Amostra Educação. [cited 2013 Oct 13]. Available at: http://cidades.ibge.gov.br/xtras/temas. php?lang=\&codmun= 350950\&idtema=105\&search=sao-paulo $\mid$ campinas $\mid$ censodemografico-2010:-resultados-da-amostra-educacao

3. Gilbert CE, Ellwein LB. Refractive Error Study in Children Study Group. Prevalence and causes of functional low vision in school-age children: results from standardized population surveys in Asia, Africa, and Latin America. Invest Ophthalmol Vis Sci. 2008:49(3):877-81.

4. Saw SM, Zhang MZ, Hong RZ, Fu ZF, Pang MH, Tan DT. Near-work activity, night-lights, and myopia in the Singapore-China study. Arch Ophthalmol. 2002;120(5):620-7.

5. Garcia CA, Oréfice F, Nobre GF, Souza D de B, Rocha ML, Vianna RN. Prevalence of refractive errors in students in Northeastern Brazil. Arq Bras Oftalmol. 2005;68(3):321-5.

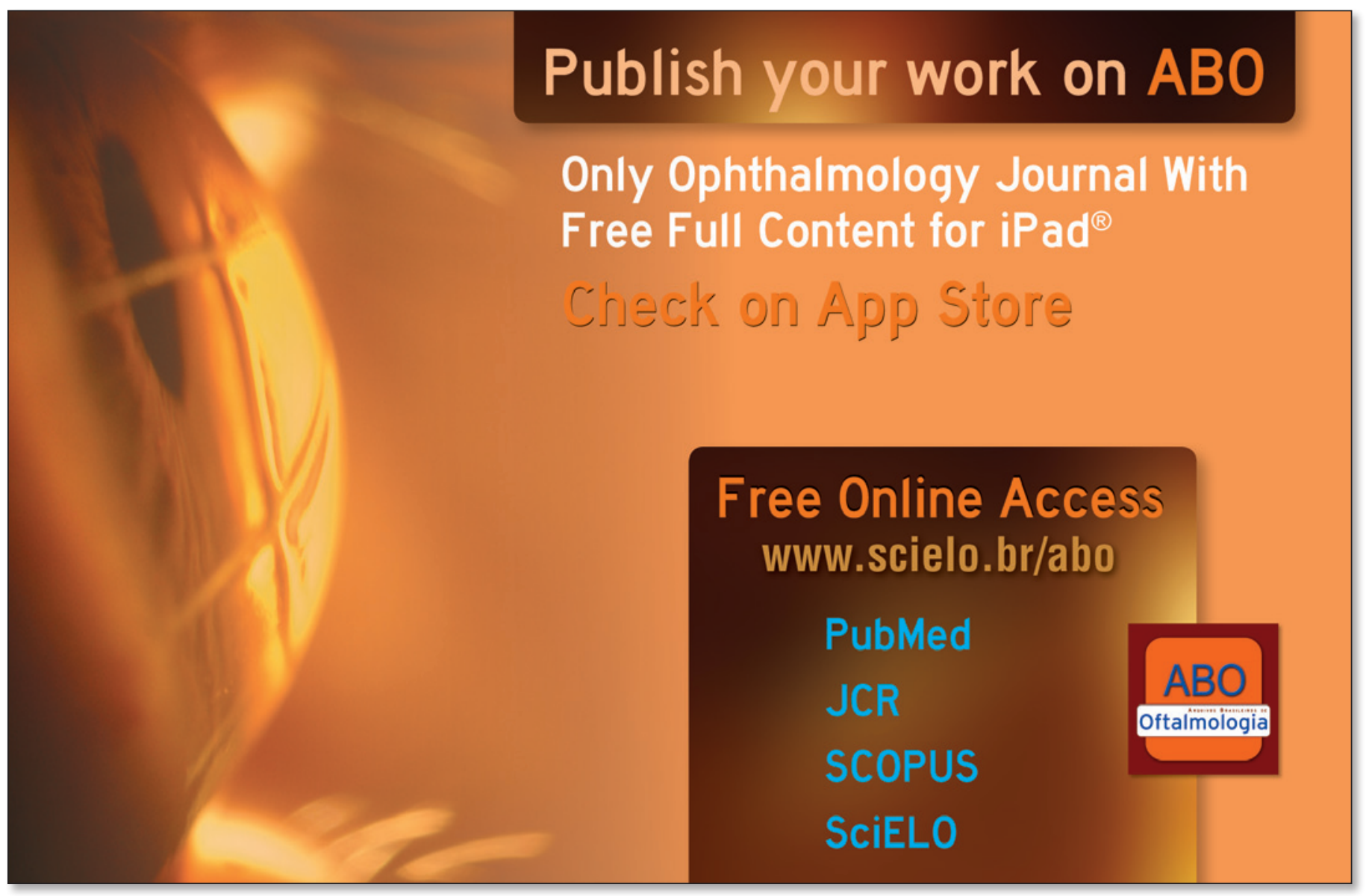

